\title{
Kündigen ohne abzumahnen?
}

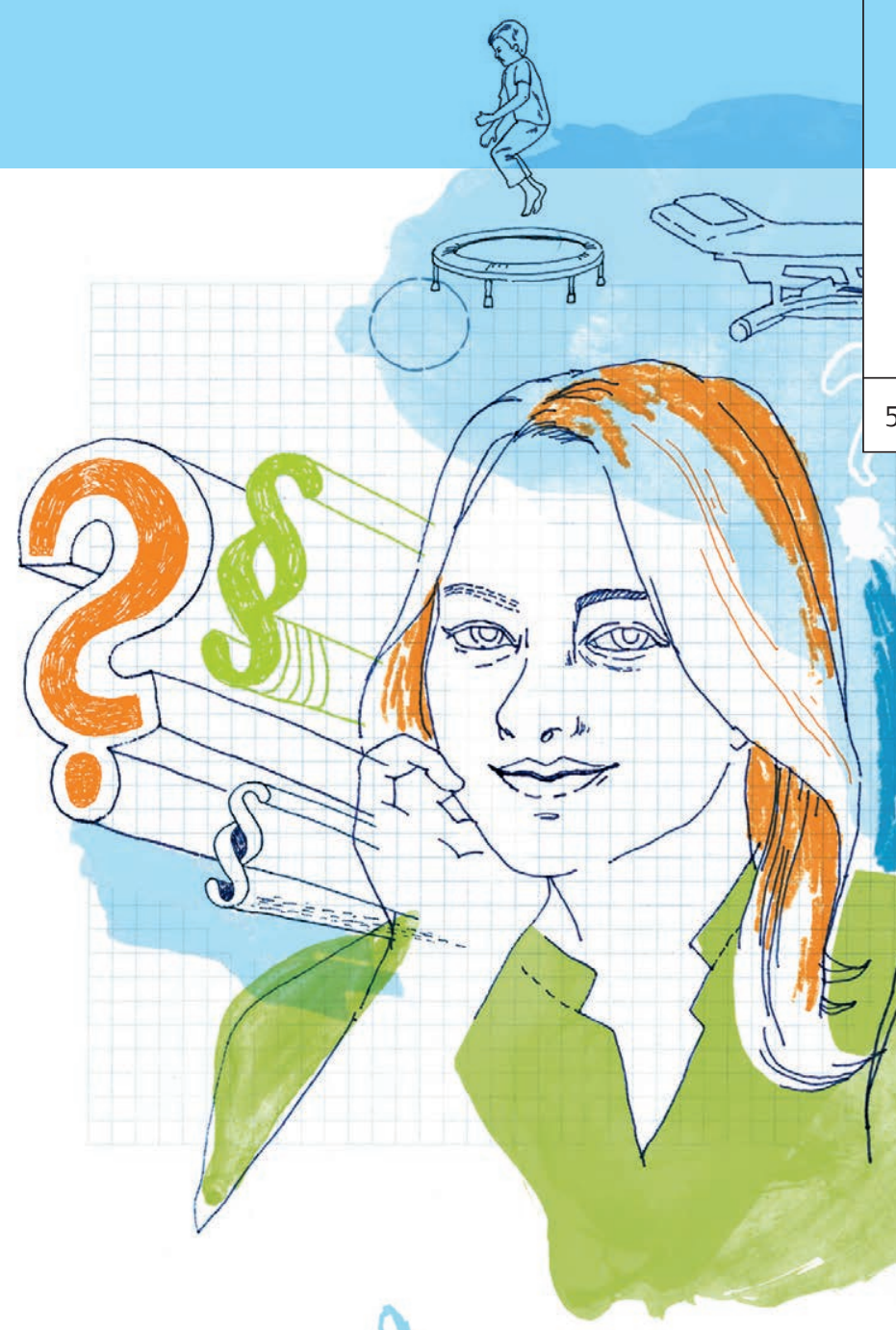

Die Antwort unseres Experten

Wie so oft lautet meine Antwort: „Es kommt darauf an.“ Richtig ist zunächst, dass die Kündigungsanforderungen in einem Kleinbetrieb mit zehn oder weniger Mitarbeitern nicht so hoch sind wie in einem größeren Betrieb. Beschäftigt der Praxisinhaber bei Ausspruch der Kündigung mehr als zehn Mitarbeiter, muss er laut Kündigungsschutzgesetz für eine ordentliche Kündigung einen Grund haben. Das heißt, er kann das Arbeitsverhältnis nur aus verhaltens-, personen- oder betriebsbedingten Gründen kündigen. Für Arbeitsverhältnisse, die bereits vor dem 1.1.2004 bestanden, gilt dies auch dann, wenn bei Kündigungsausspruch mehr als fünf Arbeitnehmer beschäftigt sind, deren Arbeitsverhältnisse vor dem 1.1.2004 begonnen haben. Bei unter fünf Mitarbeitern, wie im Fall der Fragestellerin, greift diese Bestimmung nicht.

In größeren Betrieben jedoch muss der Chef das Fehlverhalten vor Ausspruch einer verhaltensbedingten Kündigung abmahnen. Einzige Ausnahme: Wenn es sich um einen besonders schweren Verstoß handelt und der Arbeitnehmer von vornherein damit rechnen musste, dass er sein Arbeitsverhältnis aufs Spiel setzt, ist eine Kündigung auch ohne Abmahnung möglich. In einem Kleinbetrieb muss der Chef vor einer fristgerechten Kündigung grundsätzlich nicht abmahnen, solange die Kündigung nicht völlig willkürlich erfolgt. Allerdings muss er auch hier die Kündigungsfristen aus Arbeitsvertrag, Tarifvertrag oder Gesetz einhalten. Eine fristlose Kündigung kann er nur dann aussprechen, wenn für ihn die Fortsetzung des Arbeitsverhältnisses bis zum Ablauf der Kündigungsfrist oder dem Ende einer Befristung nicht zumutbar ist. Bei personen- oder betriebsbedingten Kündigungsgründen trifft das aber in der Regel nicht zu.

Meist beruht eine fristlose Kündigung auf einem Fehlverhalten des Arbeitnehmers. Ist eine Verhaltensänderung zu erwarten, müsste der Arbeitgeber das Fehlverhalten zunächst abmahnen. Oft ist der Vertragsverstoß jedoch so schwerwiegend, dass er auf eine Abmahnung verzichten kann. Dies muss der Arbeitgeber vor Ausspruch der Kündigung abwägen. Ebenso bedenken muss er den Kündigungsschutz, also zum Beispiel ob eine Arbeitnehmerin schwanger, in Elternzeit oder schwerbehindert ist.

Im Ergebnis ist die fristlose Kündigung in der Einrichtung unserer Fragestellerin nur dann rechtens, wenn das Fehlverhalten ihrer Kollegin so schwerwiegend war, dass ihre Weiterbeschäftigung für den Arbeitgeber unzumutbar ist bzw. er trotz Abmahnung nicht mit einer Verhaltensänderung rechnen kann, und wenn sie erkennen musste, dass sie mit ihrem Verhalten ihr Arbeitsverhältnis aufs Spiel setzt.

Karsten Bossow

\section{$\Rightarrow$ Wirft auch Ihr Berufsalltag rechtliche Fragen auf? Dann schreiben Sie an Simone.Gritsch@thieme.de.}

